\title{
Wild boar and red deer display high prevalences of tuberculosis-like lesions in Spain
}

\author{
Joaquín VICENTE ${ }^{a *}$, Ursula HÖFLE ${ }^{a}$, Joseba M. GARRIDO ${ }^{b}$, \\ Isabel G. FERNÁNDEZ-DE-MERA ${ }^{\mathrm{a}}$, Ramón JUSTE ${ }^{\mathrm{b}}$, Marta BARRAL ${ }^{\mathrm{b}}$, \\ Christian GORTAZAR ${ }^{\mathrm{a}}$ \\ ${ }^{a}$ IREC Instituto de Investigación en Recursos Cinegéticos (CSIC-UCLM-JCCM), \\ Ronda de Toledo s/n, 13080 Ciudad Real, Spain \\ b NEIKER Instituto Vasco de I+D Agraria. C./Berreaga 1, 48300 Derio, Spain
}

(Received 14 February 2005; accepted 24 June 2005)

\begin{abstract}
We describe the distribution of tuberculosis-like lesions (TBL) in wild boar (Sus scrofa) and red deer (Cervus elaphus) in Spain. Animals with TBL were confirmed in $84.21 \%$ of mixed populations $(n=57)$ of red deer and wild boar and in $75 \%$ of populations of wild boar alone $(n=8)$ in central and southern Spain (core area). The prevalence of TBL declined towards the periphery of this region. In the core area, the prevalence ranged up to $100 \%$ in local populations of wild boar (mean estate prevalence $42.51 \%$ ) and up to $50 \%$ in red deer (mean estate prevalence $13.70 \%$ ). We carried out exploratory statistical analyses to describe the epidemiology of TBL in both species throughout the core area. Prevalence of TBL increased with age in both species. Wild boar and red deer mean TBL prevalence at the estate level were positively associated, and lesion scores were consistently higher in wild boars than in red deer. The wild boar prevalence of TBL in wild boar did not differ between populations that were or were not cohabiting with red deer. Amongst the wild boars with TBL, $61.19 \%$ presented generalized lesions, and the proportion of generalized cases was similar between sex and age classes. In red deer, $57.14 \%$ of TBL-positive individuals presented generalized lesions, and the percentage of generalized cases increased with age class, but did not differ between the sexes. These results highlight the potential importance of wild boar and red deer in the maintenance of tuberculosis in south central Spain.
\end{abstract}

Mycobacterium tuberculosis complex / tuberculosis-like lesions / red deer / Spain / wild boar

\section{INTRODUCTION}

Tuberculosis is of major concern in Spain since this country was years ago, ahead of herd infection rates of bovine tuberculosis (BTB) of the European Union [4, 19]. Mycobacteria, especially Mycobacterium bovis, the causative agent of BTB, infect a broad host range [9, 27]. The re-emergence of $\mathrm{BTB}$, and failure to eradicate infection in livestock in many countries have been related to maintenance of reservoirs of disease in wildlife populations, such as the badger (Meles meles) [10] and the brushtail possum (Trichosurus vulpecula) [5]. Tuberculosis (TB) may however spread primarily from livestock prior to establishment in freeliving wildlife, as was the case in the African buffalo (Syncerus caffer) [32,33] which subsequently became a potential reservoir

\footnotetext{
* Corresponding author: jvicente@ irec.uclm.es
} 
of infection for other wildlife. In Spain, a similar scenario may apply since two wild ungulate species, the red deer (Cervus elap$h u s$ ) and the wild boar (Sus scrofa) have been reported to be infected with $M$. bovis $[1,2,15,16,28]$. In addition, cases of fatal tuberculosis have been described in endangered carnivores of the same region, such as the Iberian lynx (Lynx pardinus) [31]. To date, the magnitude of TB infection rates and distribution in wildlife in Spain, especially in potential reservoir species, remains unknown. This information is crucial in order to improve and optimize resources of control schemes.

During recent decades, extensive changes in land-use have been followed by a progressive decrease of cattle herds and a marked increase in wild ungulates, both in number and distribution, and the development of an important commercial hunting industry, especially in south central Spain. Among these wild ungulates, the wild boar is the most widely distributed, covering almost the entire Spanish mainland, and in the last three decades population densities have largely increased [14, 36]. Both wild boar and red deer are important game species in Spain, both because of its wide distribution and its great economic relevance [13]. Recent observational evidence suggests that wild boar population may be capable of persistent maintenance of TB infection in a cattle-free area with low red deer density [30]. Both farmed and high density free-living populations of red deer have been considered TB maintenance hosts elsewhere [9].

These changes in wildlife management have already raised concerns regarding the control of infectious and parasitic diseases $[11,38,39]$. In this context, our aims were the following: (a) to assess the occurrence and prevalence of TB-like lesions (TBL) through a nationwide survey of red deer and wild boar, and through an exploratory analysis, (b) to describe epidemiological patterns and (c) to investigate the relationships between the presence of TBL in both species.

\section{MATERIALS AND METHODS}

\subsection{Study sites}

Data was collected from a cross-sectional national survey of TB in the wild boar and wild red deer at 76 sites in Spain (Figs. 1 and $2)$. The sites were selected in order to represent all biogeographically relevant landscape types of the Iberian Peninsula. The spatial distribution of the wild boar and red deer were generally associated, but areas where only wild boar were present, either at very low densities (open hunting areas) or at very high densities (intensively managed enclosures) were also found. Sampled hunting estates ranged in size from 408 to 52000 hectares (Figs. 1 and 2).

We will describe in more detail the prevalence of TBL in the wild boar and red deer in a core area located in Ciudad Real province and its boundaries, in south central Spain $\left(37^{\circ} 13^{\prime} 48^{\prime \prime} N\right.$ to $39^{\circ} 31^{\prime} 43^{\prime \prime} N$ in latitude and from $06^{\circ} 34^{\prime} 06^{\prime \prime} \mathrm{W}$ to $2^{\circ} 25^{\prime} 54^{\prime \prime} \mathrm{W}$ in longitude, Figs. 1 and 2). The habitat in this area is characterized by Quercus ilex forest and scrublands (dominated by Cystus spp., Pistacia spp., Rosmarinus spp., Erica spp. and Phyllirea spp.) with scattered pastures and small areas of crops. This area consists of two mountain chains, Montes de Toledo and Sierra Morena, which are connected by the Guadiana river valley, a fragmented Mediterranean habitat.

In the Mediterranean woodland habitats, most of the hunting estates are devoted exclusively to boar and deer hunting, and only a few still maintain cattle. Nevertheless, cattle had been present in most estates until they were fenced for hunting purposes, several decades ago. In contrast, uses other than hunting, such as agriculture and sheep and goat breeding, are still frequent in most open hunting areas. As for alternative TB-reservoirs, badgers are scarcely found in the core area at the edge of their spatial distribution due to environmental constraints [40] and nothing is known about infection in other suitable species. 


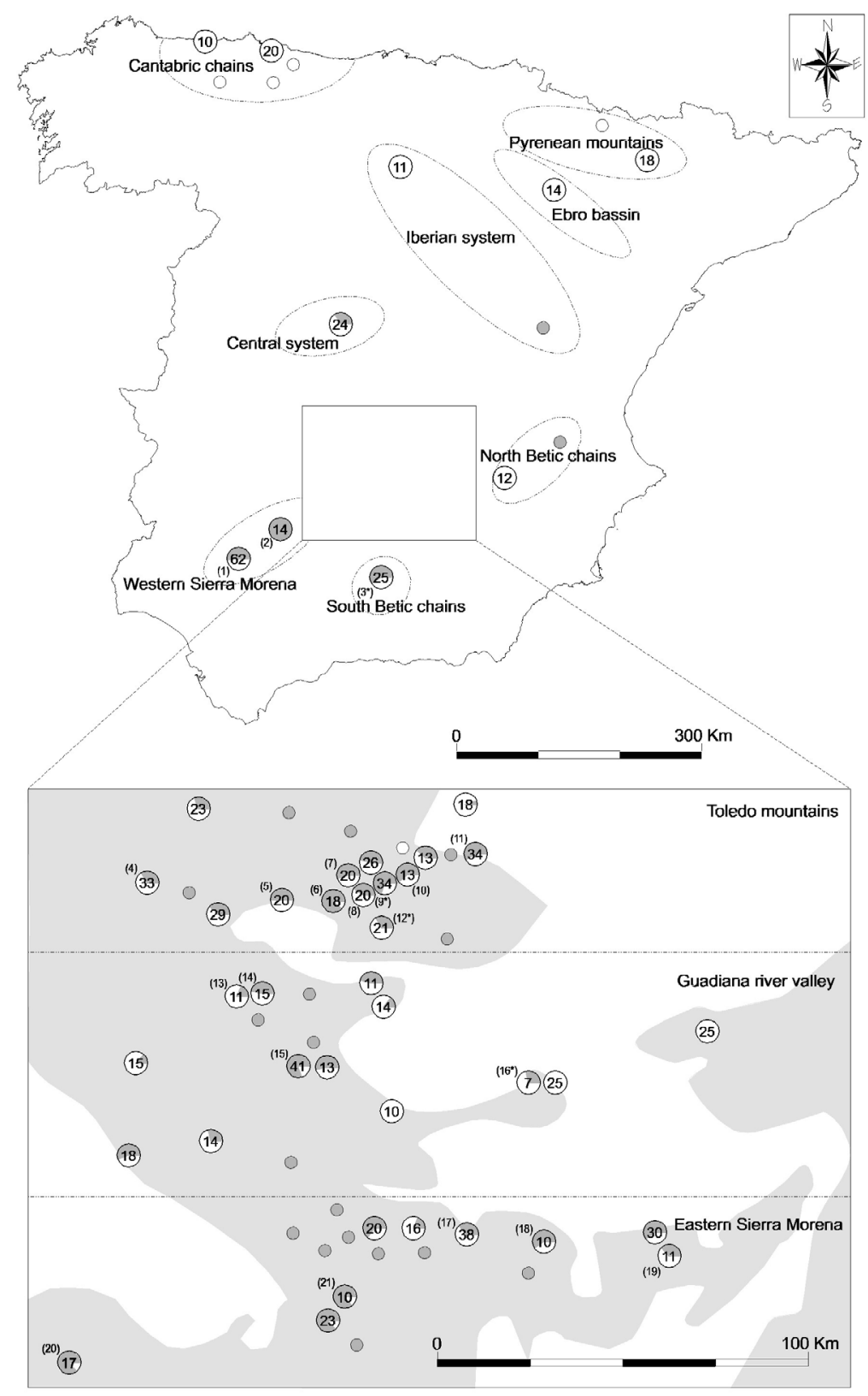

Figure 1. Map of peninsular Spain showing the sampling sites, the core area, the number of wild boars analyzed per site and the prevalence of TBL (percentage of grey color in relation to the whole circle). Dots represent sampling sites where less then 10 samples were obtained (grey color when TBL were found). Forests and scrublands are shown as grey contours. The sampling sites (Tab. I) are indicated within parentheses and * refer to sites where the red deer is absent. The epidemiology of TBL was evaluated in animals from the core area, also including Western Sierra Morena. 


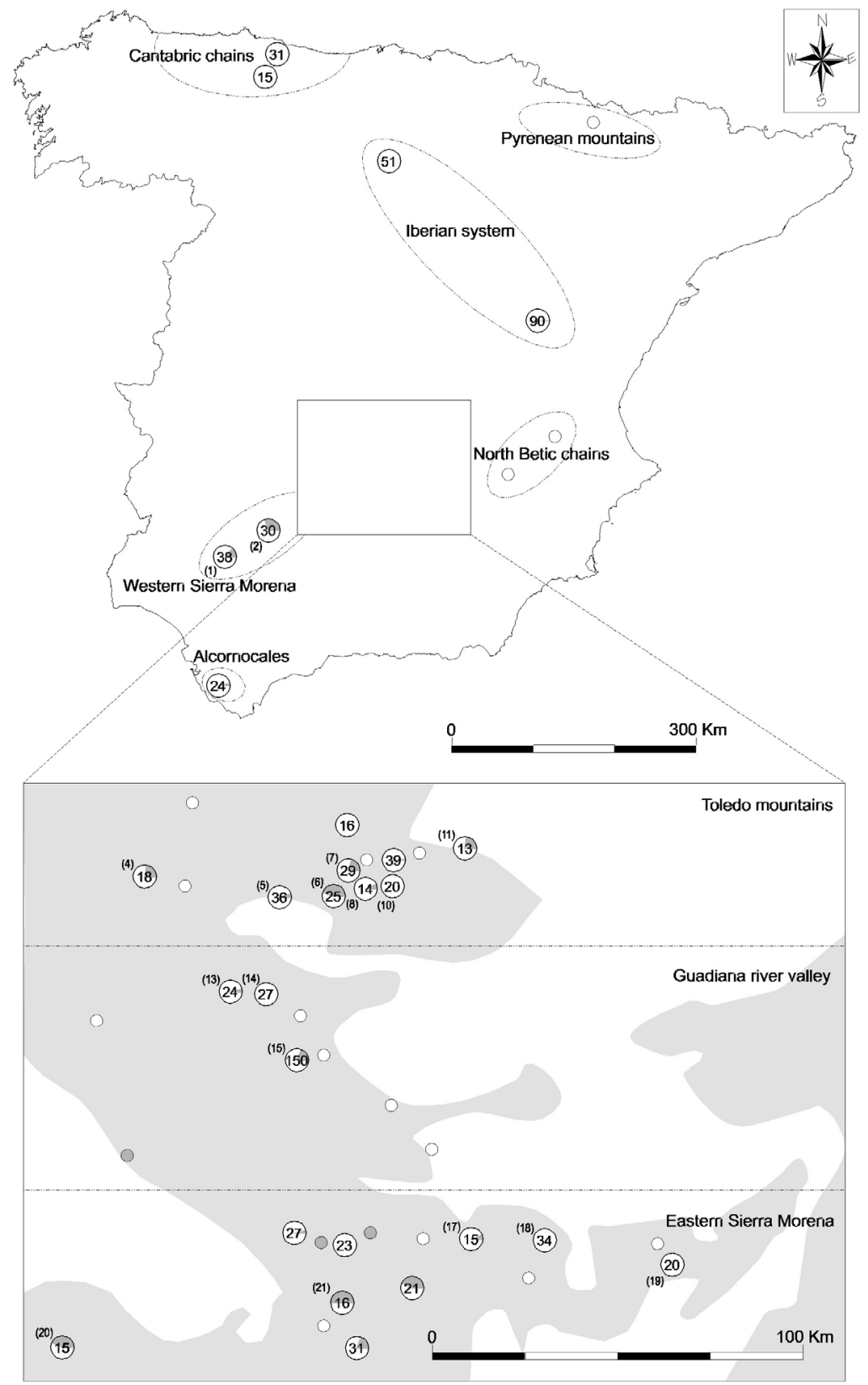

Figure 2. Map of peninsular Spain showing the sampling sites, the core area, the number of red deer analyzed per site and the prevalence of TBL (percentage of grey color in relation to the whole circle). Dots represent sampling sites where less then 10 samples were obtained (grey color when TBL were found). Forests and scrublands are shown as grey contours. The sampling sites (Tab. I) are indicated within parenthesis. The epidemiology of TBL was evaluated in animals from the core area, also including Western Sierra Morena. 


\subsection{Animal sampling}

From November 1999 to February 2004, we obtained data from 1368 red deer and 1060 wild boar harvested by hunters in the different estates, mainly from October to February (distributed as indicated in Figs. 1 and 2). In the field, we arbitrarily selected a random age and sex stratified subset of individuals of each species for examination. A necropsy was performed in the field, including detailed determination of morphometry, weight, and sex. Based on tooth eruption patterns, boars less than 7 months old were classified as piglets, boars between 7 and 12 months were classified as weaners, those between 12 and 24 months as juveniles, and those more than 2 years old as adults [35]. The ages of the red deer were precisely assessed from tooth sections [18], and were then grouped into age classes of biological meaning (according to reproductive and social status) as follows: calves ( $<1$ year), yearlings (up to 2 years old), subadults (up to 4 years old, which include females after giving birth their first offspring while subadult males are usually excluded from mating) and adults ( $\geq 5$ years).

\subsection{Presence of tuberculosis-like lesions}

TBL were diagnosed by necropsy of the entire animal with detailed macroscopic inspection of lymphodes and abdominal and thoracic organs. This examination routinely included parotid, retropharyngeal and submandibular lymphnodes in the head, tracheobronchial and mediastinal lymph nodes and lungs in the thorax, and hepatic and mesenteric lymphnodes, ileocecal valve, kidneys, liver and spleen in the abdomen. Gross lesions in other locations were also recorded. In any wild boar in which no thoracic or abdominal viscera were available, lymphoid tissues of the head alone were considered useful for diagnosis [15]. Lymph nodes were dissected, sectioned serially and carefully examined for gross lesions. Inspection of the oropharyngeal tonsils (of special interest in deer [20]) could not be carried out in all of the sampled animals. Nevertheless, we expected that infection in the retropharyngeal lymphnodes would be highly correlated with that in the tonsils [29]. We employed TBL presence in individuals as a criterion to evaluate disease distribution and in order to obtain comparable TBL rates between localities [33]. Although presence of TBL is not a perfect tool for estimating prevalence of disease, such information was considered to be valuable for exploring the magnitude and general distribution of infection in the present study given the large number of samples that were obtained from an extensive area. Rohonczy et al. [34] found that the presence of gross lesions compatible with mycobacteriosis at post-mortem inspection showed good agreement with the isolation of $M$. bovis in the case of the red deer (kappa agreement coefficient: $69 \%$ ). The presence of TB infection at the estate level was confirmed by culture [16]. We selected a random subset of positive cultures (82) from the present study and carried out molecular tests in order to determine the involvement of the Mycobacterium tuberculosis Complex (MTBC) in the observed TBL [17, 19]. In the present study we only included animals from areas in which macroscopical evidence of TB infection was supported by isolation in at least one individual.

We use the term TBL in our descriptions and analysis of prevalence. We distinguished between animals with single lesions when TBL were restricted to only a lymph node or organ in any anatomical region (i.e. head, thorax or abdomen), and generalized lesions when lesions were found in at least two different anatomical regions.

\subsection{Statistical analysis}

We evaluated the epidemiology of TBL in both species across the core area, which also included Western Sierra Morena (Figs. 1 and 2). The animals included in this exploratory analysis were distributed across sex and age classes as shown in Figure 3. We conducted two logistic regressions with 


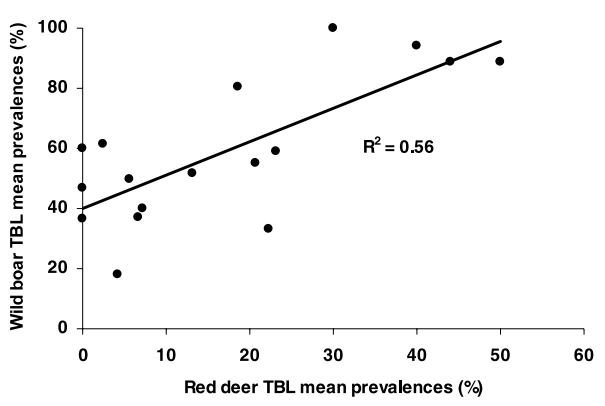

Figure 3. Relationship between wild boar and red deer TBL prevalences at the estate level.

individual status of TBL in the wild boar $(n=791)$ and red deer $(n=428)$ separately as response variables (as a binomial variable: presence or absence). We included the age classes (as described above, as an ordinal discrete variable) and sex (as a categorical factor) as explanatory variables. To test the relationship between TBL presences in both species, we included the prevalence of TBL in deer at the estate level in the wild boar model, whereas the prevalence of TBL in the wild boar was included in the deer model. Prevalence estimates were based on red deer over 2 years old and wild boar over 7 months old respectively to avoid bias due to the different sampling proportion of low prevalence classes (younger classes) across sites. We only considered individuals from sites where at least 15 red deer (in the wild boar model) and 10 wild boar (in the red deer model) were sampled to accurately assess TBL prevalence at the estate level. The models were:

Red deer TBL status $=$ sex $\times$ age $\times$ wild boar estate TBL prevalence,

Wild boar TBL status $=$ sex $\times$ age $\times$ red deer estate TBL prevalence.

We reduced the resulting models by eliminating in a backward stepwise manner any explanatory variables that failed to explain significant variation in the response variable.
We used the Spearman rank correlation to test for an association between red deer TBL prevalence and wild boar TBL prevalence (Tab. I). We also compared TBL prevalence in wild boar between populations in the core areas that were and were not cohabiting with red deer $(n=20$ and 4 respectively; $n$ for wild boars = at least 10 individuals) by means of a Mann-Whitney nonparametric test. Differences in the proportion of animals with generalized TBL across sex and age classes were tested by means of $\chi^{2}$ tests. The level of significance was established at the 5\% level. All $p$-values refer to two tailed tests. We employed SPSS 10.0.6 software.

\section{RESULTS}

The distribution of TBL in wild boar and red deer populations from the study sites is shown in Figures 1 and 2. The animals with TBL were confirmed in $84.21 \%$ of mixed populations $(n=57)$ of red deer and wild boar and in $75 \%$ of populations of wild boar alone $(n=8)$ in the core area. TBL were also found in wild boars from other disperse study sites in the south of Spain. In contrast, TBL were not found in the periphery of our study area especially in northern regions (Pyrenean Mountains, Ebro Valley and Cantabrian Chains). The northernmost area where TBL were detected was located in Ávila (in the wild boar) and Teruel (in wild boar and red deer, the isolation of $M$. bovis from red deer was confirmed by D.F. de Luco, personal communication).

In the core area, prevalence at the estate level ranged up to $100 \%$ in local populations of wild boars (mean estate prevalence $42.51 \pm 8.17 \%, n=37)$ and up to $50 \%$ in red deer (mean estate prevalence $13.70 \pm 6.88 \%$, $n=21$ ). While we usually found TBL positive boars in each estate of the core area, in the peripheral populations it was common to find either low prevalences or an absence of TBL. Wild boar and red deer mean TBL prevalences at the estate level were positively associated $\left(r_{\mathrm{s}}=0.56, p<0.05\right.$, 
Table I. Wild boar and red deer TBL prevalence (\% and 95\% C.I.) in estates from south central Spain.

\begin{tabular}{|c|c|c|c|c|c|c|}
\hline \multirow{2}{*}{ Sampling site } & \multicolumn{3}{|c|}{ Wild boar } & \multicolumn{3}{|c|}{ Red deer } \\
\hline & $\mathrm{TBL}+$ & $\mathrm{N}$ & Prevalence $(\%)$ & $\mathrm{TBL}+$ & $\mathrm{N}$ & Prevalence $(\%)$ \\
\hline$\overline{1}$ & 32 & 62 & $51.61 \pm 12.44$ & 5 & 38 & $13.16 \pm 10.75$ \\
\hline 2 & 14 & 14 & $100.00 \pm 0.00$ & 9 & 30 & $30 \pm 16.40$ \\
\hline $3 *$ & 15 & 25 & $60.00 \pm 19.20$ & & & \\
\hline 4 & 11 & 33 & $33.33 \pm 16.08$ & 4 & 18 & $22.22 \pm 19.21$ \\
\hline 5 & 10 & 20 & $50.00 \pm 21.91$ & 2 & 36 & $5.56 \pm 7.48$ \\
\hline 6 & 16 & 18 & $88.89 \pm 14.52$ & 11 & 25 & $44 \pm 19.46$ \\
\hline 7 & 11 & 20 & $55.00 \pm 21.80$ & 6 & 29 & $20.69 \pm 14.74$ \\
\hline 8 & 8 & 20 & $40.00 \pm 21.47$ & 1 & 14 & $7.14 \pm 13.49$ \\
\hline $9^{*}$ & 24 & 34 & $70.60 \pm 15.32$ & & & \\
\hline 10 & 8 & 13 & $61.54 \pm 26.45$ & 1 & 39 & $2.5 \pm 4.96$ \\
\hline 11 & 20 & 34 & $58.82 \pm 16.54$ & 3 & 13 & $23.08 \pm 22.90$ \\
\hline $12 *$ & 7 & 21 & $33.33 \pm 20.16$ & & & \\
\hline 13 & 2 & 11 & $18.18 \pm 22.79$ & 1 & 24 & $4.17 \pm 7.99$ \\
\hline 14 & 7 & 15 & $46.67 \pm 25.25$ & 0 & 27 & $0 \pm 0.00$ \\
\hline 15 & 33 & 41 & $80.50 \pm 12.13$ & 28 & 150 & $18.67 \pm 6.24$ \\
\hline $16^{*}$ & 2 & 7 & $28.60 \pm 5.71$ & & & \\
\hline 17 & 14 & 38 & $36.84 \pm 15.34$ & 1 & 15 & $6.67 \pm 12.62$ \\
\hline 18 & 6 & 10 & $60.00 \pm 30.36$ & 0 & 34 & $0 \pm 0.00$ \\
\hline 19 & 4 & 11 & $36.37 \pm 28.43$ & 0 & 20 & $0 \pm 0.00$ \\
\hline 20 & 16 & 17 & $94.12 \pm 11.19$ & 6 & 15 & $40.00 \pm 24.79$ \\
\hline 21 & 9 & 10 & $90.00 \pm 18.59$ & 8 & 16 & $50.00 \pm 24.15$ \\
\hline
\end{tabular}

* Wild boar TBL prevalence (\%) from populations where the red deer is absent. Sampling sites are represented in Figures 1 and 2.

$n=17$, Fig. 3 ) with lesion scores that always appeared to be higher in wild boar than in red deer. Interestingly, wild boar populations where red deer and/or livestock were absent also presented TBL.

The age and sex patterns of TBL presence in individual red deer and wild boar from the core area are shown in Figure 4. Both of the definitive logistic models fitted adequately (Hosmer and Lemeshow goodness-of-fit tests, Tab. II) but neither of the models explained the majority of the variation in the data (see $R^{2}$ Nagelkerke, Tab. II). There were statistically significant increasing age-prevalence patterns of TBL in both species (Tab. I, Fig. 4). The probability of TBL being present in either species was positively correlated with the prevalence of TBL in the other species (Tab. II, Fig. 3).
Prevalence of TBL in wild boar did not differ between populations cohabiting (mean estate prevalence $52.28 \pm 11.25 \%$ ) and not cohabiting with red deer (mean estate prevalence $48.13 \pm 19.97 \%$; Z: -0.28-; NS).

The distribution of generalized lesions among the wild boar $(n=211)$ and red deer $(n=98)$ with precisely described lesions is shown in Table III. Amongst the wild boar with TBL, $61.19 \%$ presented generalized lesions. The proportion of generalized cases was similar between sex and age classes ( $\chi^{2}$ test, NS 0.05 in all comparisons). Amongst the TBL-positive red deer, 57.14\% presented generalized lesions. In red deer, the percentage of generalized cases increased with age class $\left(\chi^{2}=4.02, p<0.05\right)$ but the proportion of generalized cases in males and females was similar ( $\chi^{2}$ test, NS). 
A

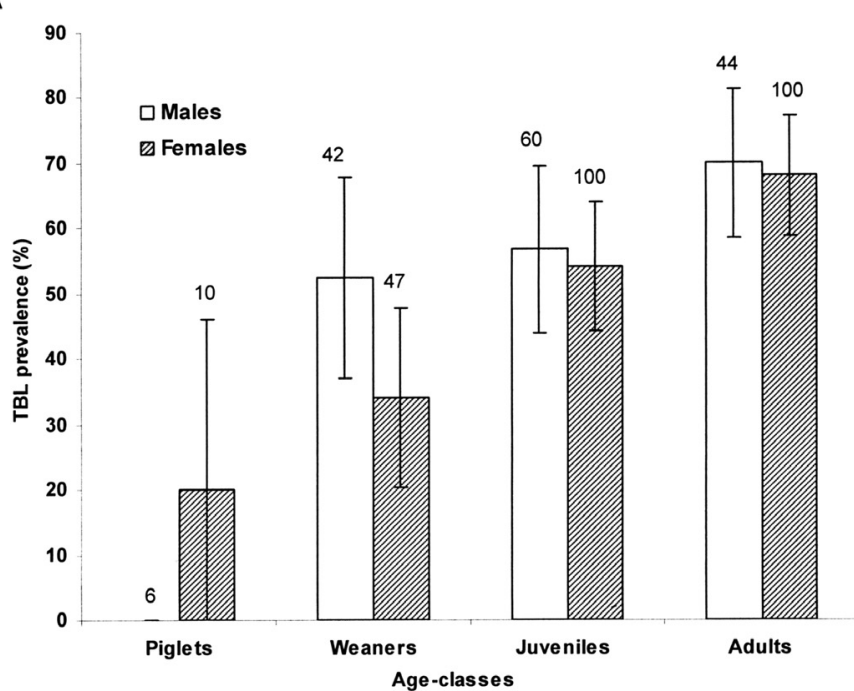

B

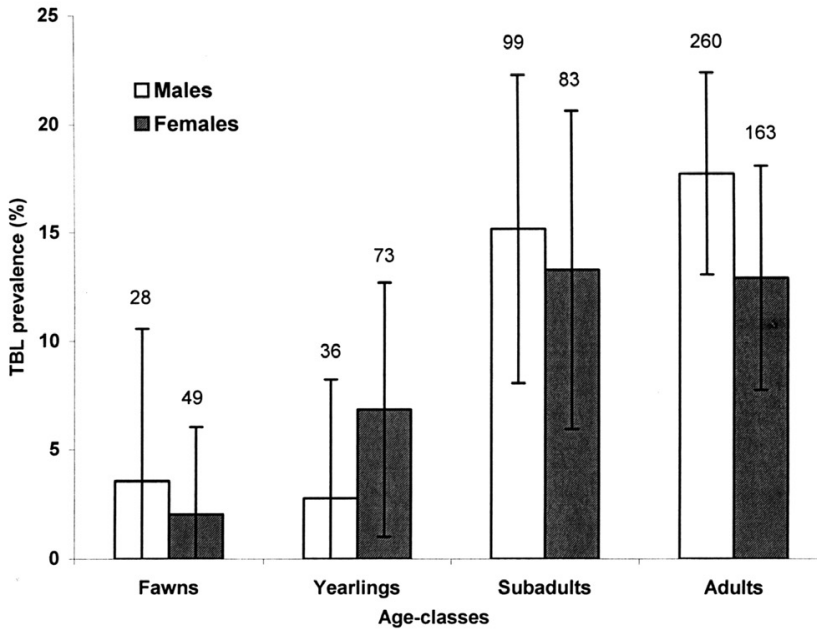

Figure 4. Age and sex TBL prevalence patterns in the wild boar (A) and red deer $(\mathbf{B})$ from the core area. Vertical lines indicate $95 \%$ confidence limits for prevalences. Sample size is indicated at the top of the bar for each sex-by-age class.

\section{DISCUSSION}

As the first survey on TBL in wild ungulates at a nationwide scale, this study reveals that the two most important wild ungulates in south central Spain show high preva- lences of macroscopic lesions. It also shows that the problem is apparently concentrated in a core area including parts of Castilla La Mancha, Extremadura and Andalucía, in south-west Spain. These are areas with high densities and intensive game-management, 
Table II. Logistic regression models for wild boar and red deer TBL status.

\begin{tabular}{lcccc}
\hline Variable & $B(\mathrm{SE})$ & Wald statistic & d.f. & $p$-value \\
\hline \multicolumn{1}{l}{ Age } & Wild boar TBL status & & & \\
Red deer TBL prevalence & $0.64(0.12)$ & 25.54 & 1 & $<0.0001$ \\
$R^{2}$ Nagelkerke: 0.17 & $0.04(0.008)$ & 25.43 & 1 & $<0.0001$ \\
Hosmer \& Lemeshow $\chi^{2}: 8.93$; NS & & & & \\
& & & & \\
Age & Red deer TBL status & & & \\
Wild boar TBL prevalence & $0.49(0.14)$ & 12.41 & 1 & $<0.001$ \\
$R^{2}$ Nagelkerke: 0.13 & $0.03(0.006)$ & 35.19 & 1 & $<0.0001$ \\
Hosmer \& Lemeshow $\chi^{2:}$ 7.09; NS & & & & \\
\hline
\end{tabular}

Table III. Distribution of generalized lesions across TBL positive wild boars and red deer (prevalence \pm S.E.). Sample size is shown within parenthesis.

\begin{tabular}{lccccc}
\hline \multicolumn{5}{c}{ Wild boar $^{\mathrm{a}}$} \\
Total $(n=211)$ & Males (103) & Females (103) & Weaners (40) & Juveniles (79) & Adults (88) \\
$61.19 \pm 3.35$ & $60.19 \pm 3.47$ & $59.22 \pm 3.42$ & $57.5 \pm 3.44$ & $63.29 \pm 3.35$ & $60.22 \pm 3.47$ \\
\multicolumn{5}{c}{ Red deer $^{\mathrm{b}}$} \\
Total (98) & Males (60) & Females (34) & Subadults (20) & Adults (66) \\
$57.14 \pm 4.99$ & $58.33 \pm 5.08$ & $52.94 \pm 5.15$ & $40.00 \pm 5.28$ & $65.15 \pm 5.14$ \\
\hline
\end{tabular}

a Sex was not recorded for 4 individuals, and age was not recorded for 5 individuals.

b Sex was not recorded for 4 individuals, and age was not recorded for 12 individuals.

including big game fencing, supplementary feeding and translocations. In contrast, game management is uncommon in northern Spain, and this may contribute to the observed geographical pattern of TBL. It cannot be guaranteed that the sample animals examined in the present study was entirely representative of the overall deer and wild boar population across Spain, but it does provide insight into the distribution of wildlife of TBL in wildlife, and may help to focus future research.

The results from the subset of isolates that underwent molecular tests, agree with the findings from previous research [16] that mycobacteria involved in TBL do belong primarily to the MTBC. Also a molecular study based on a sub-sample of the animals from the present study, found that wild boar and red deer shared the same M. tuberculo- sis complex organisms, and the comparison of suggested that the spoligotypes of these isolates were similar to those of domestic livestock and humans [16].

In spite of microbiological culture being the gold standard for the diagnosis of bovine $\mathrm{TB}$, in our experience a negative culture status in wild boar was not a guarantee that an animal was disease free (the authors, in preparation). On the contrary, other pathogens causing similar macroscopic lesions such as Actinomycetes [26], Rhodococcus equi [23] or other mycobacteria such as the M. avium complex [8] could result in an overestimation of prevalence estimated based on TBL. However, Mignone et al. [25] found that a little proportion of wild boars carried pathogens other than micobacteria in Italy. In the red deer, prevalences may have been understimated according to 
Lugton [20] and Lugton et al. [21], who suggest that up to one quarter of infected deer may show no detectable gross lesions. The use of a set of complementary techniques, particularly detailed inspection and culture of oropharyngeal tonsils should, in future studies, improve sensitivity allowing the detection of animals with early infections that do not present macroscopical lesions [20]. In conclusion, since it is impossible to quantify such bias in the prevalence estimates given here for both species, they must be considered as relative values.

The reported red deer TBL prevalences, locally reaching $50 \%$ (considering only subadult and adult animals) are high as compared to those reported in the literature in natural red deer populations (up to $37 \%$ in New Zealand, [21], but based on isolation). Lugton et al. [21] observed that the estimated prevalence in wild deer populations in the northern hemisphere was always below $6 \%$ (see also [6]). This raises the question of whether the high prevalences observed in the present study in south central Spain may reflect transmission to deer from other species.

In the case of wild boar, to our knowledge, the extremely high disease prevalence in this single host species (ranging up to $100 \%$ of the adults showing macroscopic lesions) over such a large area, is a unique situation. Enzootic TB has previously been reported in wild boar in Italy [37], with prevalences ranging up to $15 \%[3,21,24]$, in France (28.5\% based on isolation, [17]) and in other countries from central and western Europe (in Germany, 1.4\% based on gross lesions; and in 7 other countries [22]). M. bovis prevalence was recorded as $19 \%$ in feral pigs in the Northern Territory of Australia [7], dropping to $0.25 \%$ after destocking of the cattle and feral Asian buffalo water populations [24]. In New Zealand, TB prevalence of up to $31 \%$ was found in Central Otago [41] and finally a prevalence of $17.7 \%$ of TB was described in feral pigs from the Hawaiian island of Molokai (reviewed in [9]).
The percentage of wild boars with generalized lesions did not increase with age, suggesting the possibility of a certain resistance to clinical disease in this species. Corner et al. [7] concluded that, based on the low prevalence of generalised TB infection in pigs, the absence of pulmonary lesions, the lack of obvious excretion routes and the lack of contact between pigs and other infected species, transmission of $M$. bovis from live, infected pigs to cattle or feral water buffalo (Bubalus bubalis) in Australia was unlikely. Nevertheless, our findings suggest that in south central Spain wild boars with generalized TBL could potentially have at least a role in the intraspecific transmission of infection.

With regards to the epidemiological analyses, since this was a correlational study, we consider our conclusions as exploratory. We observed an overall increase of prevalence of TBL with age in both species. This is commonly reported in the literature on TB. It is mainly due to the chronicity of the infection, and to the increasing probability of acquisition of infection during life. In the case of wild boars, prevalence was already high in early life (less than one year), suggesting that the infection occurs frequently in young animals, even piglets. The population dynamics of the wild boar, with a short life span mainly due to intense hunting pressure [12], makes it difficult to study the effect of TB infection on host survival. However, in our experience, fatal cases of chronic disease were not uncommon in the affected estates (the authors, in preparation).

In red deer TBL prevalence was lower and individuals are longer-lived than wild boar. The acquisition of infection red deer seemed to occur progressively across age classes and evidence of early TB transmission was scarce. The low number of TBL positive fawns in relation to the prevalence in older animals, suggests limited importance of maternal transmission in free ranging deer from south central Spain. Similarly, in New Zealand red deer, there was no evidence of TB infection in fawns in an area 
where prevalence in their dams was about $50 \%$ [20]. Similar findings were also observed in white tailed deer from Michigan [28]. Further studies are needed to evaluate the effect of TB on red deer survival (fatal cases are known to occur) and its importance as a source of TB for wild boars that scavenge dead animals or discarded viscera. As discussed, wild boars seem to be more easily infected than red deer, even if they are apparently less prone to develop clinical disease. Management factors, which maintain high densities and spatially concentrate wild ungulates, may increase the frequency and probability of both direct and indirect transmission of TB, and this could preferably affect wild boars.

Evidence consistent with the wild boar being a potential $\mathrm{TB}$ reservoir in Spain includes the observations that in several populations where red deer were absent, TBL were found in wild boars, and the MTB complex was isolated [16]. This was most evident in two localities where alternative sources of infection than the wild boar, such as livestock, were not found. One is an area with low wild boar density (see location 16 in Tab. I and Fig. 1) and the other is an intensively managed hunting area with high wild boar abundance (see location 9). Given its ubiquitous distribution and its ability to undercross fences, the wild boar could also be responsible for the appearance of TBL in peripheral areas, by means of between-estate migration.

Epidemiologists agree that it is difficult to identify any one reservoir species with certainty (e.g. red deer and BTB in New Zealand, [21]). In the present study we found that the red deer, usually considered as a poor reservoir host, and wild boar (in mixed populations or alone), generally considered as a spill-over host, may both be able to maintain TB infection in the wild in a number of different situations. Hence, in our opinion, wild ungulates should be considered as potential TB reservoirs in Mediterranean Spain. In the future, the potential role of other species in TB epidemiology, such as small mammals, should be investigated. The mode, routes and quantity of interspecies transmission amongst wildlife and domestic cattle also have to be evaluated in the future to clarify the role of the European wild boar and the red deer as TB reservoirs in Spain.

\section{ACKNOWLEDGEMENTS}

This study was supported by project AGL20013947, MCYT and FEDER and project RTA03074-C2-2 INIA. This is also a contribution to the agreement between FG-UCLM and Grupo Santander, and to the agreement between Yolanda Fierro and the UCLM. J. Vicente had a grant from the JCCM. We wish to thank A. Peña, J.A. Ortiz, E. Arias, and all our colleagues at IREC for their kind help. J.L. Paramio revised a first draft of this manuscript.

\section{REFERENCES}

[1] Aranaz A., Liébana E., Mateos A., Domínguez L., Vidal D., Domingo M., Gonzalez O., Rodríguez-Ferri E.F., Bunschoten A.E., Van Embden J.D., Cousins D., Spacer oligonucleotide typing of Mycobacterium bovis strains from cattle and other animals: a tool for studying epidemiological of tuberculosis, J. Clin. Microbiol. 34 (1996) 2734 2740.

[2] Aranaz A., Cousins D., Mateos A., Domínguez L., Elevation of Mycobacterium tuberculosis subsp. caprae Aranaz and others 1999 to species rank as Mycobacterium caprae comb. nov., sp. nov., Int. J. Syst. Evol. Microbiol. 53 (2003) 1785-1789.

[3] Bollo E., Ferroglio E., Dini V., Mignone W., Biolatti B., Rossi L., Detection of Mycobacterium tuberculosis complex in lymph nodes of wild boar (Sus scrofa) by a target-amplified test system, J. Vet. Med. B Infect. Dis. Vet. Public Health 47 (2000) 337-342.

[4] Caffrey J.P., Status of bovine tuberculosis eradication programmes in Europe, Vet. Microbiol. 40 (1994) 1-4.

[5] Caley P., Hone J., Disease transmission between and within species, and the implications for disease control, J. Appl. Ecol. 41 (2004) 94-104. 
[6] Clifton-Hadley R.S., Wilesmith J.W., Tuberculosis in deer: a review, Vet. Rec. 129 (1991) 5-12.

[7] Corner L.A., Barrett R.H., Lepper A.W., Lewis V., Pearson C.W., A survey of mycobacteriosis of feral pigs in the Northern Territory, Aust. Vet. J. 57 (1981) 537-542.

[8] De Lisle G.W., Joyce M.A., Yates G.F., Wards B.J., Hoyle F.P., Mycobacterium avium infection in a farmed deer herd, N. Z. Vet. J. 43 (1995) 1-3.

[9] De Lisle G.W., Mackintosh C.G., Bengis R.G., Mycobacterium bovis in free-living and captive wildlife, including farmed deer, Rev. Sci. Tech. Off. Int. Epizoot. 20 (2001) 86111.

[10] Delahay R.J., De Leeuw A.S, Barlow A.M., Clifton-Hadley R.S., Cheeseman C.L., The status of Mycobacterium bovis infection in UK wild mammals: a review, Vet. J. 164 (2002) 90-105.

[11] Fernández-De-Mera I.G., Gortazar C., Vicente J., Höfle U., Fierro Y., Wild boar helminths: risks in animal translocations, Vet. Parasitol. 115 (2003) 35-41.

[12] Fernández-Llario P., Mateos-Quesada P.M. Silverio A., Santos P., Habitat effects and shooting techniques on two wild boar populations in Spain and Portugal, Z. Jagdwiss. 49 (2003) 120-129.

[13] Fierro Y., Gortazar C., Landete-Castillejos T., Vicente J., García A., Gallego L., Baseline values for cast antlers of Iberian red deer, $\mathrm{Z}$. Jagdwiss. 48 (2002) 244-251.

[14] Gortazar C., Herrero J., Villafuerte R., Marco J., Historical examination of the status of large mammals in Aragon, Spain, Mammalia 64 (2000) 411-422.

[15] Gortazar C., Vicente J., Gavier-Widen D., Pathology of bovine tuberculosis in the European wild boar (Sus Scrofa), Vet. Rec. 152 (2003) 779-780.

[16] Gortazar C., Vicente J., Samper S., Garrido J. Fernández-De-Mera I.G., Gavín P., Juste R.A., Martín C., Acevedo P., De La Puente M., Höfle U., Molecular characterization of Mycobacterium tuberculosis complex isolates from wild ungulates in South-Central Spain, Vet. Res. 36 (2005) 43-52.

[17] Hars J., Surveillance of bovine tuberculosis in the wild ungulates of the Brotonne forest (Seine-Maritime and Eure), Office National de la Chasse et de la Faune Sauvage, Rapport Scientifique, 2002, pp. 73-76.

[18] Klevezal' G.A., Kleinenberg S.E., In Age determination of mammals from annual layers in teeth and bones, Severtsov Institute of Ani- mal Morphology, Clearinghouse Fed. Sci. Tech. Inf. U.S. Dep. Commer, Springfield, 1967.

[19] Liébana E., Aranaz A., Mateos A., Vilafranca M., Gomez-Mampaso E., Tercero J.C., Alemany J., Suarez G., Domingo M., Domínguez L., Simple and rapid detection of Mycobacterium tuberculosis complex organisms in bovine tissue samples by PCR, J. Clin . Microbiol. 33 (1995) 33-36.

[20] Lugton I., Mucosa-associated lymphoid tissues as sites for uptake, carriage and excretion of tubercle bacilli and other pathogenic mycobacteria, Immunol. Cell Biol. 77 (1999) 364 372.

[21] Lugton I.W., Wilson P.R., Morris R.S., Nugent G., Epidemiology and pathogenesis of Mycobacterium bovis infection of red deer in New Zealand, N. Z. Vet. J. 46 (1998) $147-$ 156.

[22] Machackova M., Matlova L., Lamka J., Smolik J., Melicharek I., Hanzlikova M., Docekal J., Cvetnic Z., Nagy G., Lipiec M., Ocepek M., Pavlik I. Wild boar (Sus scrofa) as a possible vector of mycobacterial infections: reviews of literature and critical analysis of data from Central Europe between 1983 to 2001, Vet. Med. 48 (2003) 51-65.

[23] Meijer W.G., Prescott J.F., Rhodococcus equi, Vet. Res. 35 (2004) 383-396.

[24] McInerney J., Small K.J., Caley P., Prevalence of Mycobacterium bovis infection in feral pigs in the Northern Territory, Aust. Vet. J. 72 (1995) 448-451.

[25] Mignone W., Dini V., Bollo E., Ganduglia S., Ferraro G., Becchi R., Poggi M., Monitoraggio della tubercolosi nei cinghiali a vita libera: esperienze in provincia di Imperia e di Sadova, Suppl. Ricer. Biol. Selv. 24 (1996) 619-629.

[26] Norton J.H., Tuberculosis-like granulomas in cattle caused by Actinomycetes, Aust. Vet. J. 52 (1976) 455-457.

[27] O'Reilly L.M., Daborn C.J., The epidemiology of Mycobacterium bovis infections in animals and man: a review, Tuber. Lung Dis. 76 (1995) 1-46.

[28] O'Brien D.J., Schmitt S.M., Fierke J.S., Hogle S.A., Winterstein S.R., Cooley T.M., Moritz W.E., Diegel K.L., Fitzgerald S.D., Berry D.E., Kaneene J.B., Epidemiology of $\mathrm{Myco}$ bacterium bovis in free-ranging white-tailed deer, Michigan, USA, 1995-2000, Prev. Vet. Med. 54 (2000) 47-63.

[29] Palmer M.V., Waters W.R., Whipple D.L., Lesion development in white-tailed deer experimentally infected with Mycobacterium bovis, Vet. Pathol. 39 (2002) 334-340. 
[30] Parra A., Fernandez-Llario P., Tato A., Larrasa J., García A., Alonso J.M., De Mendoza M.H., De Mendoza J.H., Epidemiology of Mycobacterium bovis infections of pigs and wild boars using a molecular approach, Vet. Microbiol. 97 (2003) 123-133.

[31] Pérez J., Calzada J., Leon-Vizcaíno L., Cubero M.J., Velarde J., Mozos E., Tuberculosis in an Iberian lynx (Lynx pardina), Vet. Rec. 148 (2001) 414-415.

[32] Rodwell T.C., Kriek N.P., Bengis R.G., Whyte I.J., Viljoen P.C., De Vos V., Boyce W.M., Prevalence of bovine tuberculosis in African buffalo at Kruger National Park, J. Wild. Dis. 37 (2001) 258-264.

[33] Rodwell T.C., Whyte I.J., Boyce W.M., Evaluation of population effects of bovine tuberculosis in free-ranging African buffalo, J. Mammal. 82 (2001) 231-238.

[34] Rohonczy E.B., Balachandran A.V., Dukes T.W. Payeur J.B., Rhyan J.C., Saari D.A. Whiting T.L., Wilson S.H., Jarnagin J.L., A comparison of gross pathology, histopathology, and mycobacterial culture for the diagnosis of tuberculosis in elk (Cervus elaphus), Can. J. Vet. Res. 60 (1996) 108-114.

[35] Sáenz De Buruaga M., Lucio A.J., Purroy J., Reconocimiento de sexo y edad en especies cinegéticas, Diputación Foral de Alava, Vitoria, 1991
[36] Sáez-Royuela C., Tellería J.L., The increased population of the wild boar (Sus scrofa L.) in Europe, Mammal. Rev. 16 (1986) 97-101.

[37] Serraino A., Marchetti G., Sanguinetti V., Rossi M.C., Zanoni R.G., Catozzi L., Bandera A., Dini W., Mignone W., Franzetti F., Gori A., Monitoring of transmission of tuberculosis between wild boars and cattle: genotypical analysis of strains by molecular epidemiology techniques, J. Clin. Microbiol. 37 (1999) 2766-2771.

[38] Vicente J., Segalés J., Höfle U., Balasch M., Plana-Durán J., Domingo M., Gortazar C., Epidemiological study on porcine circovirus type 2 (PCV2) infection in the European wild boar (Sus scrofa), Vet. Res. 35 (2004) 243253.

[39] Vicente J., Ruiz-Fons F., Vidal D., Höfle U., Acevedo P., Villanúa D., Fernández-de-Mera I.G., Martín M.P., Gortazar C., Serosurvey of Aujeszky's disease virus infection in European wild boar in Spain, Vet. Rec. 156 (2005) 408-412.

[40] Virgós E., Casanovas J.G., Environmental constraints at the edge of a species distribution, the Eurasian badger: a biogeographic approach, J. Biogeography 26 (1999) 559564.

[41] Wakelin C.A., Churchman O.T., Prevalence of bovine tuberculosis in feral pigs in Central Otago, Surveillance 18 (1991) 19-20. 